TITLE:

\title{
Near-infrared spectroscopy underestimates cerebral oxygenation in hemodialysis patients
}

\author{
AUTHOR(S):
}

Matsukawa, Shino; Kai, Shinichi; Mizota, Toshiyuki

\section{CITATION:}

Matsukawa, Shino ...[et al]. Near-infrared spectroscopy underestimates cerebral oxygenation in hemodialysis patients. Journal of Anesthesia 2019, 33(3): 478-481

\section{ISSUE DATE:}

2019-06

URL:

http://hdl.handle.net/2433/243861

\section{RIGHT:}

This is a post-peer-review, pre-copyedit version of an article published in 'Journal of Anesthesia'. The final authenticated version is available online at: https://doi.org/10.1007/s00540-019-02650-4.; The full-text file will be made open to the public on 06 May 2020 in accordance with publisher's 'Terms and Conditions for Self-Archiving', この論文 は出版社版でありません。引用の際には出版社版をご確認ご利用ください。; This is not the published version. Please cite only the published version. 


\section{Article Title:}

Near-infrared spectroscopy underestimates cerebral oxygenation in hemodialysis patients

\section{Authors:}

Shino Matsukawa, MD, Shinichi Kai, MD, PhD, Toshiyuki Mizota, MD, PhD

\section{Institutions:}

Department of Anesthesia, Kyoto University Hospital, Kyoto, Japan

\section{Corresponding Author:}

Toshiyuki Mizota,

Department of Anesthesia, Kyoto University Hospital

54 Shogoin-Kawahara-Cho, Sakyo-Ku, Kyoto 606-8507, Japan

Phone: $+81-75-751-3433$

Fax: $+81-75-752-3259$

Email: mizota@kuhp.kyoto-u.ac.jp

\section{Key words:}

Near-infrared spectroscopy, Hemodialysis, Regional cerebral oxygen saturation, jugular venous oxygen saturation

Word count excluding abstract and references): 1500 words

Number of tables: 1

Number of figures: 1 


\begin{abstract}
Regional cerebral oxygen saturation $\left(\mathrm{rSO}_{2}\right)$ measured using near-infrared spectroscopy has been reported to be significantly lower in hemodialysis (HD) patients than in nonHD ones, but the mechanisms are unknown. The aim of this prospective study was to assess the accuracy of near-infrared spectroscopy to estimate cerebral oxygenation in HD patients undergoing cardiovascular surgery. Our hypothesis was that $\mathrm{rSO}_{2}$ values would underestimate cerebral oxygenation in HD patients. This study included 113 patients (7 HD patients and 106 non-HD ones) undergoing cardiac or major aortic surgery between December 2015 and November 2017. We evaluated the validity of $\mathrm{rSO}_{2}$ by comparing it with ipsilateral jugular venous oxygen saturation $\left(\mathrm{SjvO}_{2}\right)$. In $\mathrm{HD}$ and non-HD patients, $\mathrm{rSO}_{2}$ and $\mathrm{SjvO}_{2}$ showed a weak correlation $\left(\mathrm{R}^{2}: 0.46\right.$ and 0.28 in HD and non-HD patients, respectively). Bland-Altman analysis revealed that bias (95\% limits of agreement) of $\mathrm{rSO}_{2}$ compared to $\mathrm{SjvO}_{2}$ was $-19.2 \%(-41.7 \%$ to $3.3 \%)$ in $\mathrm{HD}$ patients and $-1.9 \%(-19.3 \%$ to $15.5 \%)$ in non-HD ones. The large negative bias suggests that the $\mathrm{rSO}_{2}$ values measured using near-infrared spectroscopy substantially underestimate cerebral oxygenation in HD patients.
\end{abstract}




\section{Introduction}

Regional cerebral oxygen saturation $\left(\mathrm{rSO}_{2}\right)$ measured using near-infrared spectroscopy (NIRS) provides non-invasive and real-time estimation of cerebral oxygenation and has been increasingly used in a variety of clinical settings, e.g., cardiac surgery [1]. The use of NIRS to measure cerebral oxygenation has been validated in healthy adults [2]. However, $\mathrm{rSO}_{2}$ measurement using NIRS technology is influenced by various factors, including cerebral arterial/venous blood partitioning, skull thickness, and cerebrospinal fluid (CSF) area [1].

Some reports, including our own, have demonstrated that $\mathrm{rSO}_{2}$ values are significantly lower in hemodialysis (HD) patients when compared to non-HD ones [3-5]. Although there are several possible explanations for low $\mathrm{rSO}_{2}$ levels in $\mathrm{HD}$ patients, including decreased cerebral perfusion [3, 6], metabolic acidosis [7], and increased area of the CSF layer due to cerebral atrophy [8], the specific cause of the reduced $\mathrm{rSO}_{2}$ values in HD patients remains unknown.

The primary aim of the study was to assess the accuracy of NIRS to estimate cerebral oxygenation in HD patients undergoing cardiovascular surgery. Preoperative $\mathrm{rSO}_{2}$ values were compared to jugular venous oxygen saturation $\left(\mathrm{SjvO}_{2}\right)$, an indirect indicator of global cerebral oxygenation [9], in HD and non-HD patients. We hypothesized that $\mathrm{rSO}_{2}$ values would underestimate cerebral oxygenation in $\mathrm{HD}$ patients. 


\section{Methods}

This prospective study was approved by the ethics committee at Kyoto University. All participants provided written, informed consent to participate. Adults aged $\geq 20$ years who underwent cardiac or major aortic surgery at Kyoto University Hospital between December 1, 2015 and November 30, 2017 were included. Based on previous research [5], we estimated that about 180 patients met the inclusion criteria during the 2-year study period, of which approximately 30 were dependent on HD. Additionally, other investigations have shown that the standard deviation (SD) of the difference between $\mathrm{rSO}_{2}$ and $\mathrm{SjvO}_{2}\left(\Delta \mathrm{SO}_{2}\right)$ is estimated to be $10 \%$ [2]. With the probability of type I error set at 0.05 and a sample size of 180 , the chance of detecting a $5 \%$ and $10 \%$ difference in $\Delta \mathrm{SO}_{2}$ between $\mathrm{HD}$ and non-HD patients is $70.1 \%$ and $99.9 \%$, respectively. Considering that a $\Delta \mathrm{SO}_{2}>10 \%$ is clinically significant, this sample size would be considered adequate for the purpose of this investigation.

Data collected from the electronic medical records of participants, included age, gender, weight, height, other comorbidities, and preoperative examination findings. In patients who preoperatively underwent computed tomography (CT) scans, the area of frontal CSF layer [10] and skull thickness [8] were calculated from CT images, which included the anterior horn of the lateral ventricle.

Upon entering the operating room, the $\mathrm{rSO}_{2}$ values were obtained using the INVOS 5100C system (Somanetics, Troy, MI). Probes containing light sources provided two continuous wavelengths of near-infrared light (730 and $810 \mathrm{~nm})$, reaching a brain area corresponding to the junction between the anterior and middle cerebral artery vascularization territory. Two probes were attached to the right and left sides of the forehead with the inferior border approximately $1 \mathrm{~cm}$ above the eyebrow and the medial 
edge at midline. General anesthesia was induced, and patients were tracheally intubated and mechanically ventilated. Blood from the internal jugular vein was collected through cervical puncture of the pulmonary artery catheter or central venous catheter insertion. The $\mathrm{SjvO}_{2}$ values were measured from internal jugular vein blood samples with RapidLab 1265 (Siemens, Erlangen, Germany) and the $\mathrm{rSO}_{2}$ values were simultaneously recorded from the ipsilateral side.

Data were analyzed using JMP version 8.0 (SAS Institute Japan Ltd., Tokyo, Japan). Continuous data were presented as median (interquartile range), and categorical variables as number (percentage). Differences between groups were compared using the Mann-Whitney U test for continuous variables, and Pearson's chi-square or Fisher's exact tests for categorical variables. Linear regression analysis was used to assess the association between continuous variables. The agreement between $\mathrm{rSO}_{2}$ and $\mathrm{SjvO}_{2}$ values across all subjects was assessed using a Bland-Altman plot. The degree of error, defined as the difference between $\mathrm{rSO}_{2}$ and $\mathrm{SjvO}_{2}$ values, was assessed in terms of parametric analysis of the errors, including bias (mean of the difference between $\mathrm{rSO}_{2}$ and $\mathrm{SjvO}_{2}$ values), $\mathrm{SD}$, and $95 \%$ limits of agreement. All statistical tests were twotailed, and the probability of type I error was set at 0.05 . This manuscript adheres to the Guidelines for Reporting Reliability and Agreement Studies [11]. 


\section{Results}

A total of 180 patients underwent cardiac or major aortic surgery during the study period. Of these, 27 did not provide written informed consent and were excluded. Additionally, 23 patients whose $\mathrm{SjvO}_{2}$ was not measured and 17 whose $\mathrm{rSO}_{2}$ values were not properly collected were excluded; the remaining 113 were included in the analysis. Among these 113, 7 (5.9\%) preoperatively received HD. All HD patients had been on dialysis for at least 1 year at the time of surgery (median: 8 years). HD patients had significantly lower $\mathrm{rSO}_{2}$ values than non-HD ones $[44.6 \%(31.1 \%-58.0 \%)$ vs. $67.4 \%(65.7 \%-69.1 \%) ; \mathrm{P}<0.01]$. The area of CSF layer was significantly greater in HD patients than non-HD ones [4.8 (3.8-5.8) vs. $3.6(3.2-4.0) ; \mathrm{P}=0.032]$. There was no statistically significant difference in skull thickness between groups (Table 1).

Linear regression analysis showed that the average slope and intercept for $\mathrm{rSO}_{2}$ versus $\mathrm{SjvO}_{2}$ were 0.66 and 34.4, respectively, in $\mathrm{HD}$ patients and 0.59 and 29.2, respectively, in non-HD patients (Supplementary Figure 1). In $\mathrm{HD}$ and non-HD patients, $\mathrm{rSO}_{2}$ and $\mathrm{SjvO}_{2}$ showed a weak correlation $\left(\mathrm{R}^{2}: 0.46\right.$ and 0.28 in $\mathrm{HD}$ and non-HD patients, respectively; Supplementary Figure 1). Bland-Altman analysis revealed a significantly greater bias for $\mathrm{rSO}_{2}$ compared to $\mathrm{SjvO}_{2}$ in $\mathrm{HD}$ patients compared to non-HD patients (HD, $-19.2 \%$; non-HD, $-1.9 \% ; \mathrm{P}<0.001$; Figure 1). SDs of the error in HD and nonHD patients were $11.5 \%$ and $8.9 \%$, respectively; $95 \%$ limits of agreement ranged from $-41.7 \%$ to $3.3 \%$ and from $-19.3 \%$ to $15.5 \%$ in HD and non-HD patients, respectively (Figure 1).

Finally, we assessed the association between the area of CSF layer or skull thickness and $\Delta \mathrm{SO}_{2}$ in a subsample of patients who had preoperative CT scans $(\mathrm{n}=74)$. The correlation between the area of CSF layer and $\Delta \mathrm{SO}_{2}$ was weak but statistically 
significant $\left(\mathrm{R}^{2}, 0.05 ; \mathrm{P}=0.047\right.$; Supplementary Figure 2). No correlation was observed between skull thickness and $\Delta \mathrm{SO}_{2}$ (Supplementary Figure 3). 


\section{Discussion}

In this study, we compared $\mathrm{rSO}_{2}$ measured using $\mathrm{NIRS}$ to $\mathrm{SjvO}_{2}$, a widely used marker of global cerebral oxygenation [9]. When compared to $\mathrm{SjvO}_{2}, \mathrm{rSO}_{2}$ substantially underestimated cerebral oxygenation in HD patients. To the best of our knowledge, this is the first report to assess the accuracy of NIRS in HD patients and demonstrate substantial underestimation of cerebral oxygenation by NIRS in HD patients.

Although several possible explanations for low $\mathrm{rSO}_{2}$ in $\mathrm{HD}$ patients have been suggested [3, 6-8], the precise mechanisms are unknown. In this study, $\mathrm{rSO}_{2}$ values were lower than $\mathrm{SjvO}_{2}$ values by approximately $20 \%$ in $\mathrm{HD}$ patients, whereas $\Delta \mathrm{SO}_{2}$ in non-HD patients was $-1.9 \%$. These data suggest that underestimation of cerebral oxygenation by NIRS is, at least in part, responsible for the low $\mathrm{rSO}_{2}$ values in $\mathrm{HD}$ patients, which brings into question the validity of cerebral oxygenation monitoring through NIRS in HD patients. Previous studies demonstrated that HD patients showed cerebral atrophy corresponding to approximately 10-20 years of chronological age [3] and an increase in CSF layer area [12] compared to controls. Further, Yoshitani et al. [8] demonstrated a negative correlation between the area of the CSF layer and $\mathrm{rSO}_{2}$ value. Thus, these data would suggest that the mechanism for the underestimation of cerebral oxygenation by $\mathrm{rSO}_{2}$ may be due to the increase in the area of the CSF layer, which reduces the intensity of near-infrared light that the detector receives. In our study, the correlation between the area of CSF layer and $\Delta \mathrm{SO}_{2}$ was significant but very weak. Additionally, the association between skull thickness and $\Delta \mathrm{SO}_{2}$ was assessed as skull thickness may influence the distance from the probe to surface of the brain, affecting the $\mathrm{rSO}_{2}$ values. No significant correlation between skull thickness $\Delta \mathrm{SO}_{2}$ was observed. These data would suggest that neither the CSF layer area nor skull thickness play a large 
role in the underestimation of cerebral oxygenation seen using NIRS. Further research is required to elucidate the mechanisms, by which cerebral oxygenation is underestimated through NIRS in HD patients.

This study had various limitations. First, continuous monitoring of $\mathrm{rSO}_{2}$ and $\mathrm{SjvO}_{2}$ would have been preferred to estimate the reliability and accuracy of $\mathrm{rSO}_{2}$. However, we only collected $\mathrm{rSO}_{2}$ and $\mathrm{SjvO}_{2}$ simultaneously at one time-point. Continuous monitoring of $\mathrm{SjvO}_{2}$ through internal jugular vein retrograde catheterization is considered relatively invasive. Therefore, a blood sample collected through a single venipuncture was used. The small sample size is another limitation. However, it was sufficient to support our initial hypothesis, because $\Delta \mathrm{SO}_{2}$ was much larger than we expected before the study.

In conclusion, this study demonstrates that $\mathrm{rSO}_{2}$ values measured using NIRS substantially underestimate cerebral oxygenation in HD patients. Further research is needed to elucidate the specific mechanism of this underestimation in cerebral oxygenation.

\section{Acknowledgments}

This work was supported in part by JSPS KAKENHI (grant number: 16K20092). 


\section{References}

1. Murkin JM, Arango M. Near-infrared spectroscopy as an index of brain and tissue oxygenation. Br J Anaesth. 2009;103:i3-13.

2. Kim MB, Ward DS, Cartwright CR, Kolano J, Chlebowski S, Henson LC. Estimation of jugular venous $\mathrm{O}_{2}$ saturation from cerebral oximetry or arterial $\mathrm{O}_{2}$ saturation during isocapnic hypoxia. J Clin Monit Comput. 2000;16:191-199.

3. Prohovnik I, Post J, Uribarri J, Lee H, Sandu O, Langhoff E. Cerebrovascular effects of hemodialysis in chronic kidney disease. J Cereb Blood Flow Metab. 2007;27:18611869.

4. Ito K, Ookawara S, Ueda Y, Goto S, Miyazawa H, Yamada H, Kitano T, Shindo M, Kaku Y, Hirai K, Yoshida M, Hoshino T, Nabata A, Mori H, Yoshida I, Kakei M, Tabei K. Factors affecting cerebral oxygenation in hemodialysis patients: cerebral oxygenation associates with $\mathrm{pH}$, hemodialysis duration, serum albumin concentration, and diabetes mellitus. PLoS One. 2015;10:e0117474.

5. Matsukawa S, Hamada M, Mizota T. Low preoperative regional cerebral oxygen saturation in hemodialysis patients. JA Clin Rep. 2017; 3:13.

6. Papadopoulos G, Dounousi E, Papathanasiou A, Papathanakos G, Tzimas P. Cerebral oximetry values in dialyzed surgical patients: a comparison between hemodialysis and peritoneal dialysis. Ren Fail. 2013;35:855-859.

7. Opdahl H, Stromme TA, Jorgensen L, Bajelan L, Heier HE. The acidosis-induced right shift of the $\mathrm{HbO}_{2}$ dissociation curve is maintained during erythrocyte storage. Scand J Clin Lab Invest. 2011;71:314-321. 
8. Yoshitani K, Kawaguchi M, Miura N, Okuno T, Kanoda T, Ohnishi Y, Kuro M. Effects of hemoglobin concentration, skull thickness, and the area of the cerebrospinal fluid layer on near-infrared spectroscopy measurements. Anesthesiology. 2007; 106:458-462.

9. Schell RM, Cole DJ. Cerebral monitoring: Jugular venous oximetry. Anesth Analg. 2000;90:559-566.

10. Kamata T, Hishida A, Takita T, Sawada K, Ikegaya N, Maruyama Y, Miyajima H, Kaneko E. Morphologic abnormalities in the brain of chronically hemodialyzed patients without cerebrovascular disease. Am J Nephrol. 2000;20:27-31.

11. Kottner J, Audige L, Brorson S, Donner A, Gajewski BJ, Hróbjartsson A, Roberts C, Shoukri M, Streiner DL. Guidelines for Reporting Reliability and Agreement Studies (GRRAS) were proposed. J Clin Epidemiol. 2011;64:96-106.

12. Drew DA, Bhadelia R, Tighiouart H, Novak V, Scott TM, Lou KV, Shaffi K, Weiner DE, Sarnak MJ. Anatomic brain disease in hemodialysis patients: a cross-sectional study. Am J Kidney Dis. 2013;61:271-278. 
Table 1. Patient characteristics stratified by HD.

\begin{tabular}{|c|c|c|c|}
\hline & $\begin{array}{l}\text { Non-HD patients } \\
\qquad(\mathrm{n}=106)\end{array}$ & HD patients $(n=7)$ & $P$ value \\
\hline Age (years) & $67(64-69)$ & $73(63-84)$ & 0.027 \\
\hline Female gender & $34(32.1 \%)$ & $3(42.86 \%)$ & 0.556 \\
\hline Wight (kg) & $62.5(59.8-65.1)$ & $62.5(52.2-72.8)$ & 0.504 \\
\hline Height (m) & $1.62(1.60-1.65)$ & $1.58(1.50-1.67)$ & 0.302 \\
\hline Hypertension & $28(73.7 \%)$ & $9(81.8 \%)$ & 0.708 \\
\hline Diabetes mellitus & $31(29.3 \%)$ & $3(42.9 \%)$ & 0.163 \\
\hline ASO & $2(1.9 \%)$ & $1(14.3 \%)$ & 0.048 \\
\hline LVEF (\%) & $60.4(57.7-63.0)$ & $56.2(43.3-69.1)$ & 0.236 \\
\hline Area of CSF layer $\left(\mathrm{cm}^{2}\right)$ & $3.6(3.2-4.0)$ & $4.8(3.8-5.8)$ & 0.032 \\
\hline Skull thickness $(\mathrm{cm})$ & $1.10(1.00-1.19)$ & $1.18(0.43-1.92)$ & 0.800 \\
\hline Mean arterial pressure (mmHg) & $75(66-86)$ & $67(57-71)$ & 0.047 \\
\hline $\begin{array}{l}\text { Percutaneous oxygen saturation } \\
(\%)\end{array}$ & $100(99-100)$ & $100(99-100)$ & 0.834 \\
\hline $\begin{array}{l}\text { Internal jugular vein blood gas } \\
\text { analysis }\end{array}$ & & & \\
\hline $\mathrm{pH}$ & $7.38(7.37-7.39)$ & $7.36(7.33-7.39)$ & 0.078 \\
\hline $\begin{array}{l}\text { Partial pressure of carbon } \\
\text { dioxide }(\mathrm{mmHg})\end{array}$ & $45.7(43.1-49.2)$ & $48.1(43.8-51.4)$ & 0.374 \\
\hline $\begin{array}{l}\text { Partial pressure of oxygen } \\
(\mathrm{mmHg})\end{array}$ & $42.4(38.4-47.0)$ & $39.4(34.9-46.9)$ & 0.656 \\
\hline Base Excess (mmol/L) & $0.95(0.47-1.44)$ & $0.51(-1.94-2.97)$ & 0.34 \\
\hline
\end{tabular}




$\begin{array}{llll}\text { Hemoglobin concentration } & 11.8(11.4-12.1) & 10.7(9.6-11.8) & 0.025\end{array}$

$(\mathrm{g} / \mathrm{dL})$

\begin{tabular}{lcrc}
\multicolumn{1}{c}{$\mathrm{SjvO}_{2}(\%)$} & $69.6(61.7-77.2)$ & $60.5(56.7-78.7)$ & 0.292 \\
$\mathrm{rSO}_{2}(\%)$ & $67.4(65.7-69.1)$ & $44.6(31.1-58.0)$ & 0.003 \\
$\mathrm{rSO}_{2}-\mathrm{SjvO}_{2}(\%)$ & $-1.7(-8.3$ to 4.7$)$ & $-19.7(-28.2$ to -6.5$)$ & $<0.001$
\end{tabular}

Area of CSF layer and skull thickness measured in 6 HD and 68 non-HD patients who preoperatively underwent head computed tomography scan. Mean arterial pressure and percutaneous oxygen saturation at the timing of internal jugular vein blood sampling was recorded. HD, hemodialysis; ASO, arteriosclerosis obliterans; LVEF, left ventricular ejection fraction; $\mathrm{rSO}_{2}$, regional cerebral oxygen saturation 


\section{Figure legend}

Figure 1. Bland-Altman plots demonstrating the agreement between $\mathrm{rSO}_{2}$ and $\mathrm{SjvO}_{2}$ of HD patients (Figure 1A) and non-HD patients (Figure 1B). The y-axis represents the difference between $\mathrm{rSO}_{2}$ and $\mathrm{SjvO}_{2}$, and the $\mathrm{x}$-axis represents the mean of $\mathrm{rSO}_{2}$ and $\mathrm{SjvO}_{2}$. The solid line represents mean bias between $\mathrm{rSO}_{2}$ and $\mathrm{SjvO}_{2}$, and the dashed lines represent limits of agreement. $\mathrm{rSO}_{2}$, regional cerebral oxygen saturation; $\mathrm{SjvO}_{2}$, jugular venous saturation; $\mathrm{HD}$, hemodialysis

A

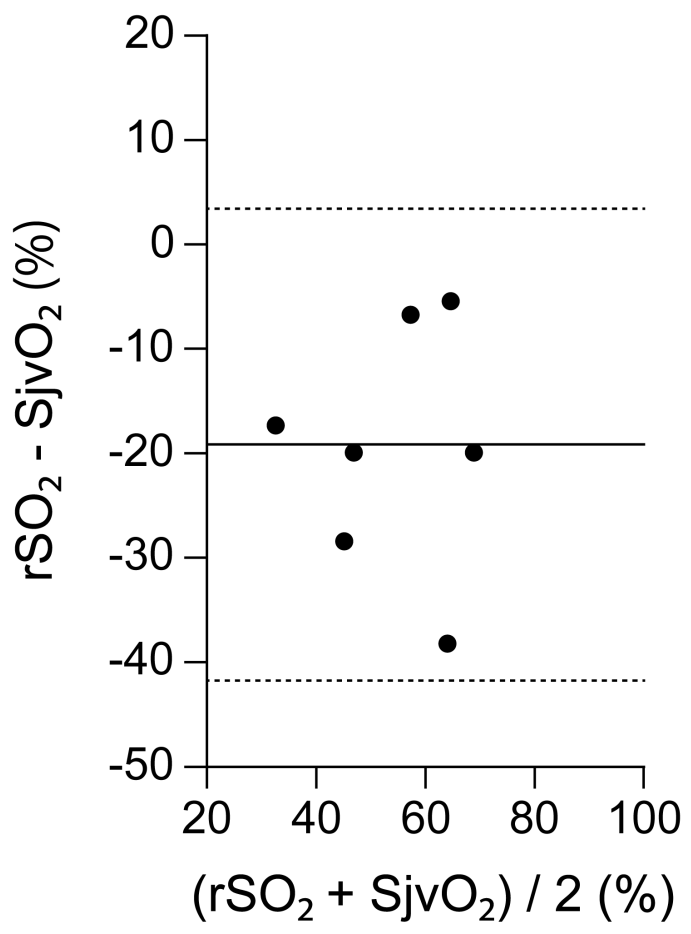

B

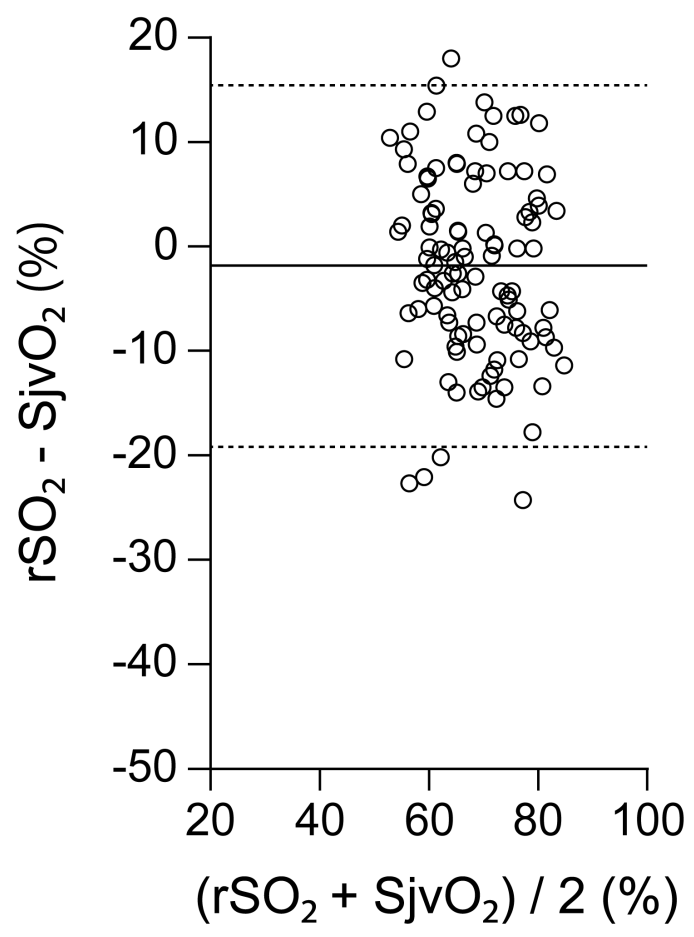




\section{Supplementary materials}

Supplement to: Matsukawa S, Kai S, Mizota T. Near-infrared spectroscopy underestimates cerebral oxygenation in hemodialysis patients. J Anesth.

Correspondence to Toshiyuki Mizota; mizota@kuhp.kyoto-u.ac.jp 
Supplementary Figure 1. Scatter plot of $\mathrm{rSO}_{2}$ and $\mathrm{SjvO}_{2}$. The solid line represents the linear regression line for HD patients, whereas the dashed line represents that for non$\mathrm{HD}$ patients. $\mathrm{rSO}_{2}$, regional cerebral oxygen saturation; $\mathrm{SjvO}_{2}$, jugular venous saturation; HD, hemodialysis

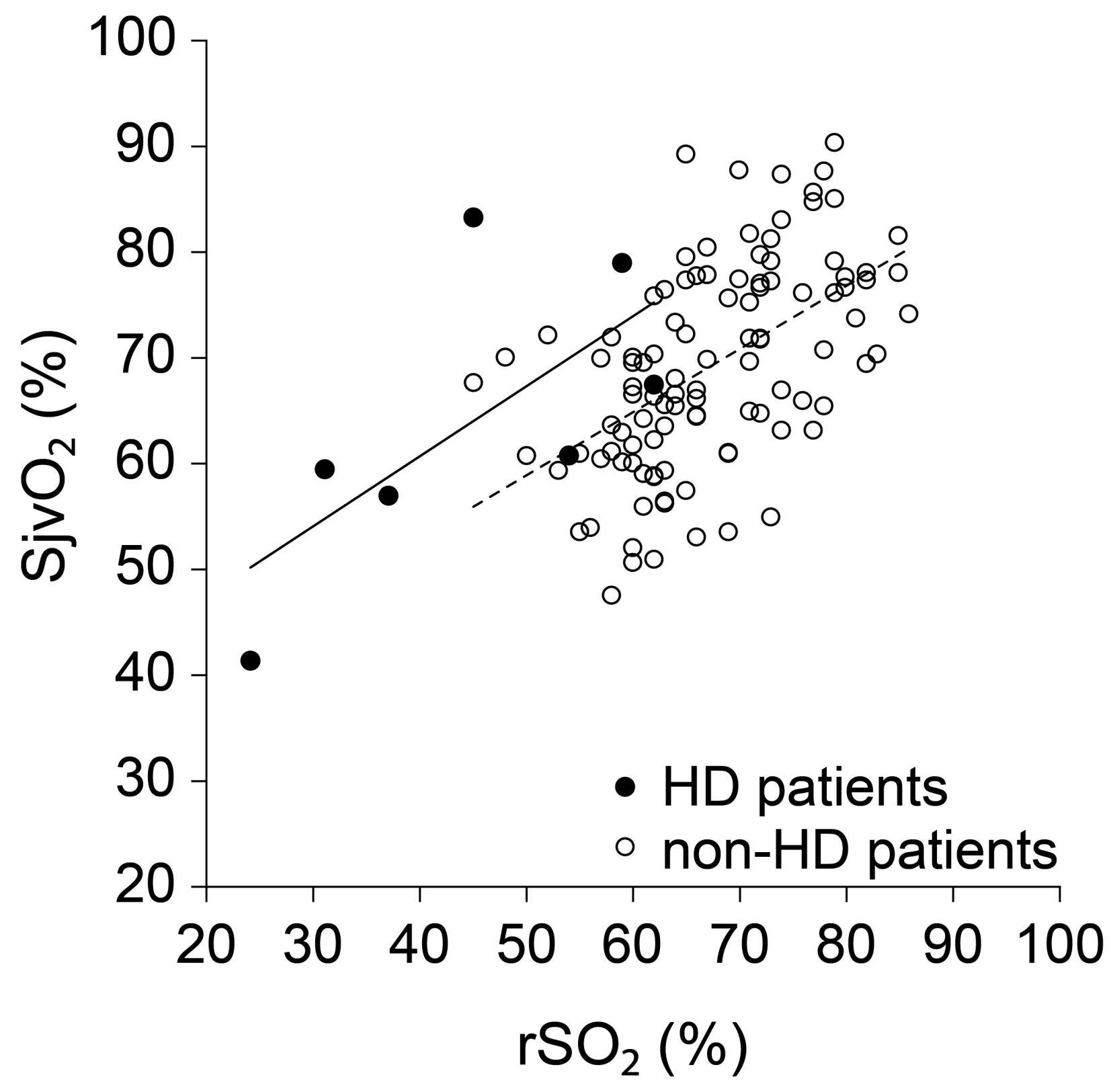


Supplementary Figure 2. Scatter plot of area of CSF layer and the difference between $\mathrm{rSO}_{2}$ and $\mathrm{SjvO}_{2}$. Area of CSF layer measured in $6 \mathrm{HD}$ and 68 non-HD patients who preoperatively underwent head computed tomography scan. The solid line represents the linear regression line for all patients. $\mathrm{rSO}_{2}$, regional cerebral oxygen saturation; $\mathrm{SjvO}_{2}$, jugular venous oxygen saturation; $\mathrm{HD}$, hemodialysis

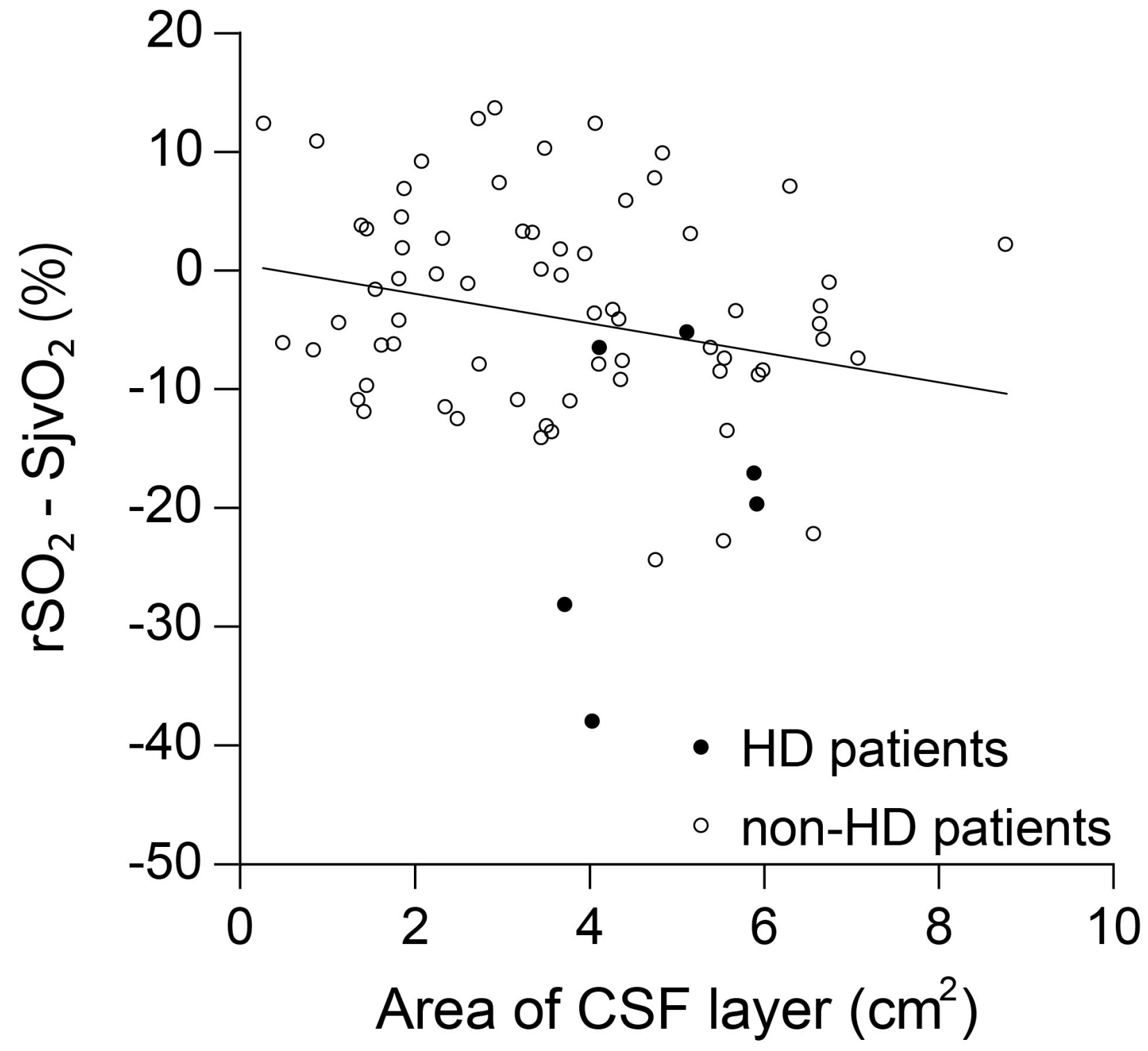


Supplementary Figure 3. Scatter plot of skull thickness and the difference between $\mathrm{rSO}_{2}$ and $\mathrm{SjvO}_{2}$. Skull thickness measured in $6 \mathrm{HD}$ and 68 non-HD patients who preoperatively underwent head computed tomography scan. $\mathrm{rSO}_{2}$, regional cerebral oxygen saturation; $\mathrm{SjvO}_{2}$, jugular venous oxygen saturation; $\mathrm{HD}$, hemodialysis

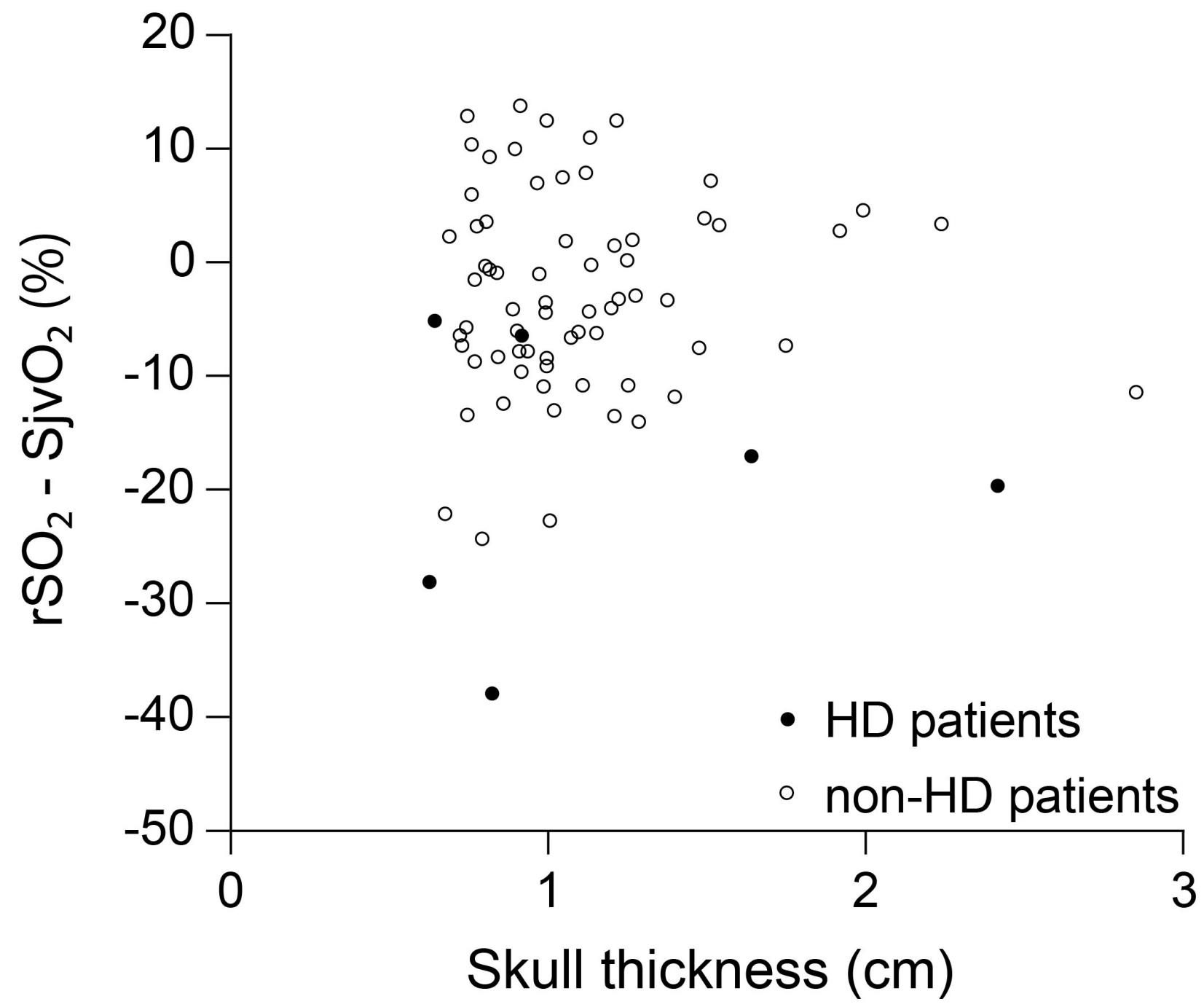

